\title{
Total synthesis of spiroketal containing natural products: kinetic vs. thermodynamic approaches
}

\author{
Mariana El Sous, Danny Ganame, Shannon Zanatta, and Mark A. Rizzacasa* \\ School of Chemistry, The Bio21 Institute, 30 Flemington Rd, The University of Melbourne, \\ Parkville, Victoria 3010, AUSTRALIA \\ E-mail: masr@unimelb.edu.au
}

\begin{abstract}
This review details part of a lecture delivered at the $20^{\text {th }}$ ICHC in Palermo Italy, July 31-August 5 2005. The published total syntheses of reveromycin A (1) and the assigned structure for spirofungin B (26) are described. The approach to $\mathbf{1}$ utilized a hetero-Diels-Alder reaction to construct the spiroketal fragment in a kinetic stereocontrolled manner. The synthesis of the proposed spirofungin B (26) spiroketal fragment utilized a thermodynamically controlled cyclization of a protected dihydroxyketone precursor. This allowed for the reassignment of the structure of spirofungin B as epi-spirofungin A (48).
\end{abstract}

Keywords: Reveromycins, spiroketal, hetero-Diels-Alder, spirofungins

\section{Contents}

1. Total synthesis of (-)-Reveromycin A

2. Total synthesis of the proposed Structure for Spirofungin B: a reassignment of the stereochemistry

\section{Total synthesis of (-)-Reveromycin A}

The reveromycins A (1) and B (2) are members of a family of compounds isolated from the soil actinomycete Steptomyces sp. ${ }^{1}$ Reveromycin A (1) is a potent inhibitor $\left(\mathrm{IC}_{50} 0.7 \mu \mathrm{gmL}^{-1}\right.$ ) of the mitogenic activity of epidermal growth factor (EGF) in a mouse keratinocyte. In addition, compound 1 exhibits antiproliferative activity against human tumor cell lines $\left(\mathrm{IC}_{50}=1.3-2.0\right.$ $\mu \mathrm{gmL}^{-1}$ ) as well as antifungal activity (MIC $\left.=2.0 \mu \mathrm{gmL}^{-1}, \mathrm{pH} 3\right) .{ }^{1 \mathrm{~b}}$ Recently, reveromycin A (1) has been identified as a specific inhibitor of Saccharomyces cerevisiae isoleucyl-tRNA synthetase (IleRS) using yeast genetics and biochemical studies. ${ }^{2}$ 


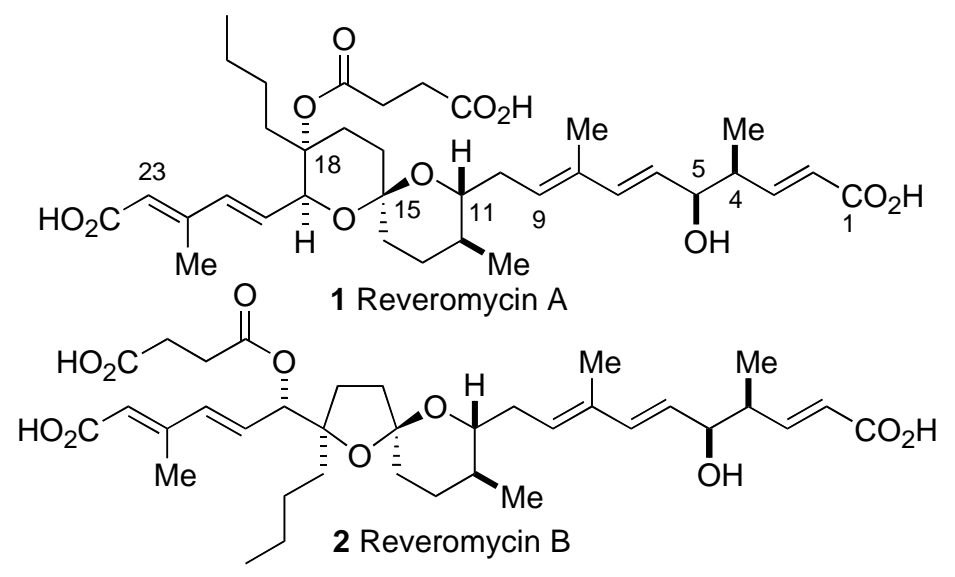

So far, only one total synthesis of $\mathbf{1}$ has been reported ${ }^{3}$ and several approaches to the 6,6spiroketal core have been described ${ }^{4-6}$ while three total syntheses of reveromycin B (2), have been completed. ${ }^{7-9}$ The total synthesis of (-)-reveromycin A (1) has been achieved ${ }^{10}$ utilizing a hetero-Diels-Alder (HDA) strategy to construct the challenging spiroketal moiety of this molecule. ${ }^{6}$

\section{Figure 1}

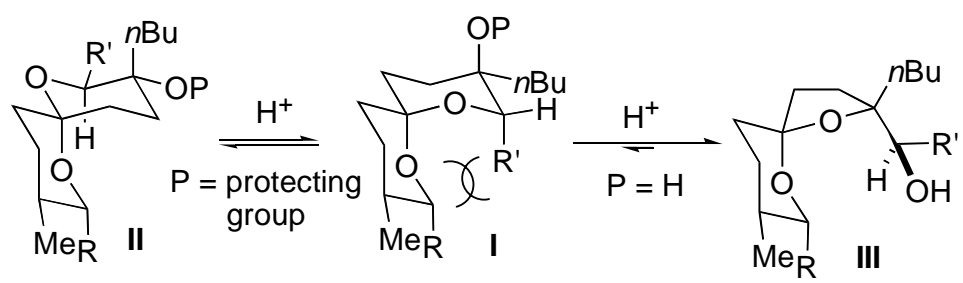

It is known that the reveromycin A (1) type 6,6-spiroketal core I can undergo acid catalyzed isomerization to afford the spiroisomer II due to an unfavorable steric interaction involving the axial C19 side chain in I which is alleviated in II, albeit at the cost of an anomeric effect (Figure 1).

Thus, the energy difference between the 6,6-spiroketals I and II is small. In addition, when the C18 alcohol is free, acid induced isomerization provides the more stable reveromycin B (2) 5,6-spiroketal core III exclusively. This energy profile has been observed in the reported thermodynamic approaches (i.e. cyclization of a 'dihydroxyketone' precursor) to the 6,6spiroketal of 1 which provided mixtures of spiroisomers ${ }^{3,4,5}$ while degradative ${ }^{4,11}$ and synthetic studies $^{6,7,9 b, 12}$ have demonstrated the strong preference for the reveromycin B type 5,6-spiroketal III. 

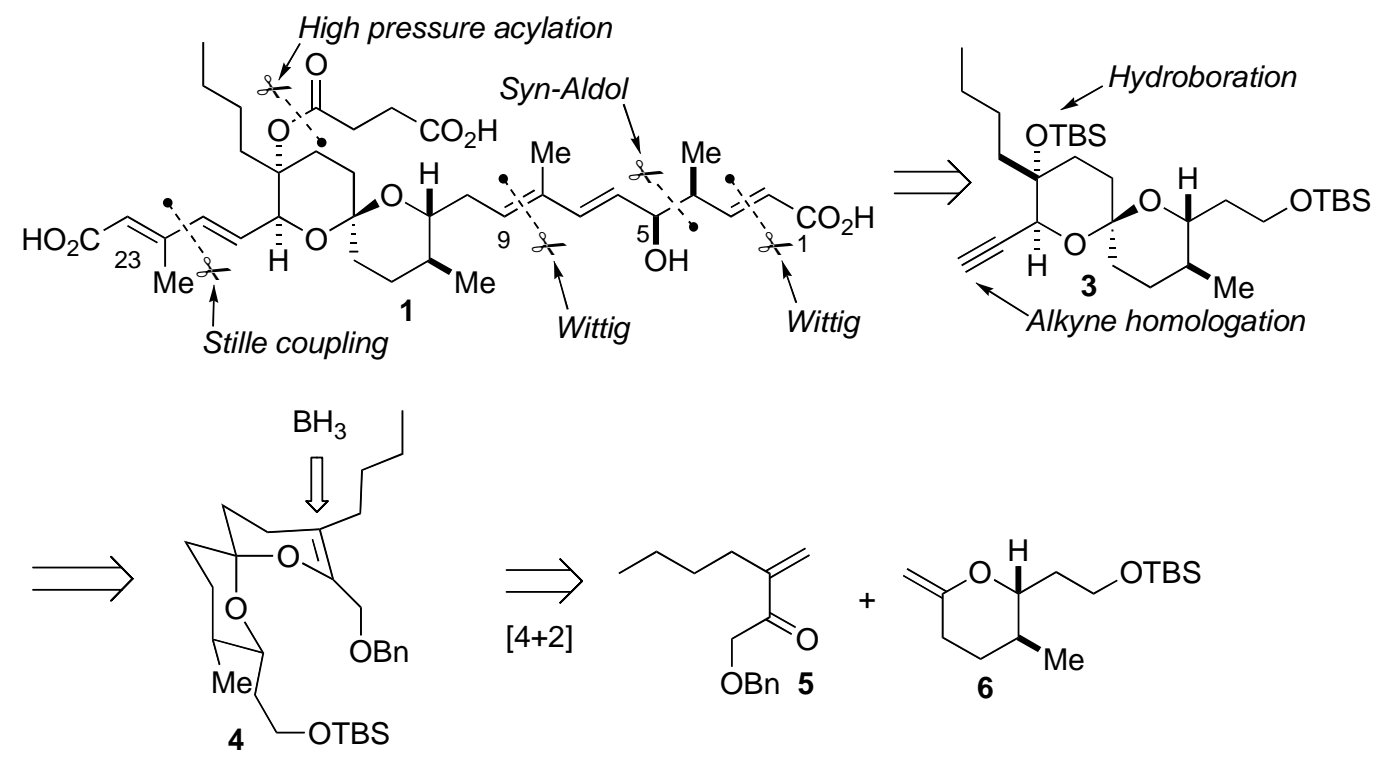

\section{Scheme 1}

In light of the above results, we envisioned that a kinetic approach to the reveromycin A spiroketal may circumvent the thermodynamic dilemma cited above. As shown in Scheme 1, the indicated retrosynthetic disconnections of 1 lead to the intermediate 6,6-spiroketal 3. This could be obtained from unsaturated spiroketal $\mathbf{4}$ by regio- and stereoselective hydroboration from the direction shown followed by alkyne homologation. Key spiroketal $\mathbf{4}$ could be obtained by an inverse electron demand HDA reaction ${ }^{13}$ between the diene $5^{6}$ and the chiral methylene pyran $\mathbf{6}^{9}$ This critical reaction should set the stereochemistry at the spiro center by an axial approach of the carbonyl oxygen in the HDA transition state. ${ }^{9}$ The stereochemistry at C18 and C19 is then set by the hydroboration/oxidation sequence which circumvents the thermodynamic lability of the reveromycin A type spiroketal $\mathbf{I}$. In addition to being stereoselective and convergent, this route would also avoid the need for a large number of different protecting groups.
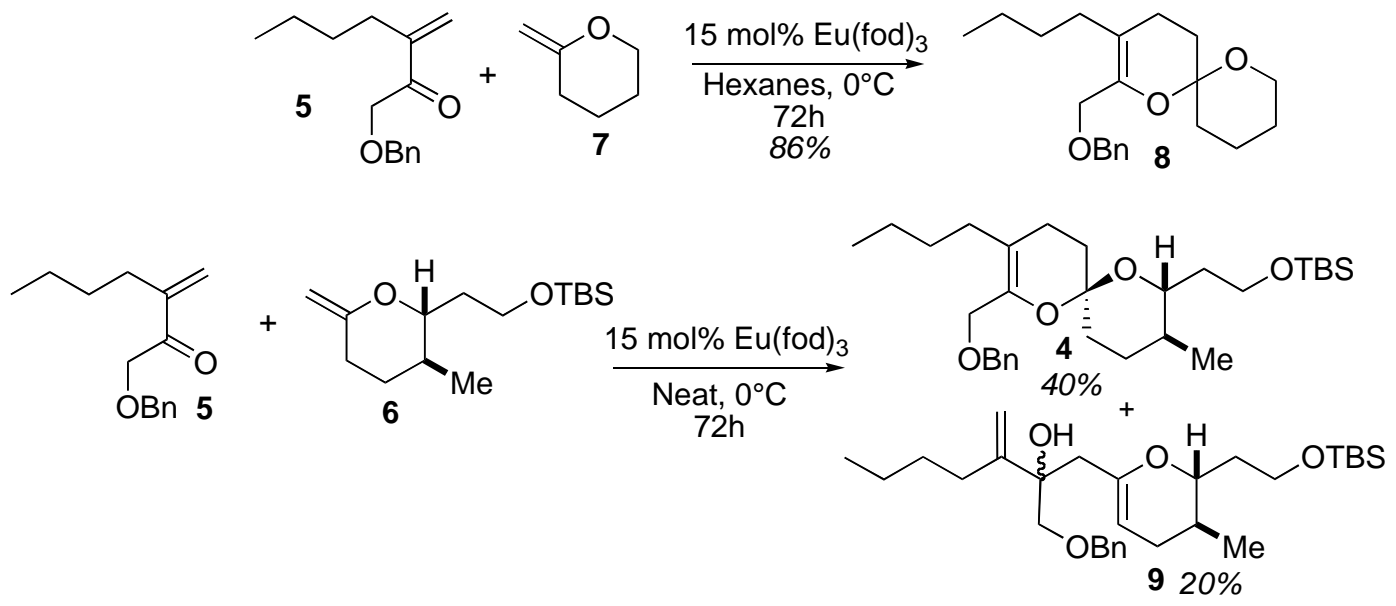

\section{Scheme 2}


Earlier, we had found that the HDA reaction of isomerizable methylene pyrans with simple hetero dienes can be achieved thermally in the presence of $\mathrm{K}_{2} \mathrm{CO}_{3}$, which effectively reduced the amount of the thermodynamically driven exo to endo isomerization of the dienophile. ${ }^{6,9}$ In the case of diene 5, using this additive gave low yields of spiroketal due to the base lability of the diene. ${ }^{6}$ Therefore, Lewis acid promotion of the cycloaddition was surveyed using the diene and model dienophile 7 (Scheme 2). After some experimentation, we found that the HDA between 7 and diene 5 was promoted by $\mathrm{Eu}(\mathrm{fod})_{3}{ }^{14}$ in hexane solvent at $0^{\circ} \mathrm{C}$ to give the spiroketal 8 in excellent yield. Unfortunately, in the case of the substituted methylene pyran $\mathbf{6}$ required for the synthesis of $\mathbf{1}$, no HDA reaction was observed in hexane solvent and only slow isomerization occurred to give the endo isomer of $\mathbf{6}$. Eventually, we found that the cycloaddition proceeded smoothly when a neat mixture ${ }^{15}$ of the diene $\mathbf{5}$ and dienophile $\mathbf{6}$ was treated with 15 mol\% $\mathrm{Eu}(\mathrm{fod})_{3}$ at $0^{\circ} \mathrm{C}$. Although the reaction gave the desired spiroketal $\mathbf{4}$ as one diastereoisomer in a higher yield than that obtained using $\mathrm{K}_{2} \mathrm{CO}_{3}$, ${ }^{6}$ the byproduct $\mathbf{9}$, resulting from an ene reaction, was also isolated as a mixture of diastereoisomers. This was not observed during the studies using the model pyran 7. The HDA reaction between 5 and 6 was also promoted by $\mathrm{ZnCl}_{2}$ in THF at $0^{\circ} \mathrm{C}$ to provide the adduct 4 in a comparable yield.

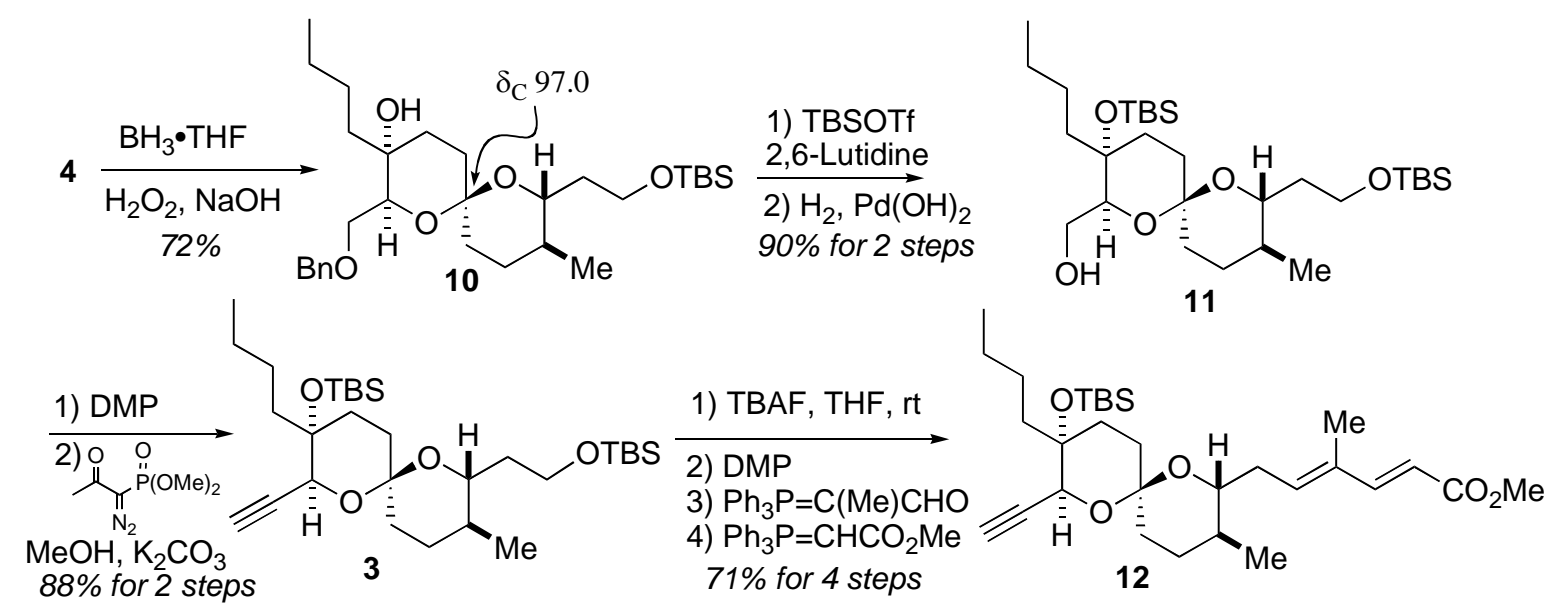

\section{Scheme 3}

With the desired spiroketal in hand, we next tackled the introduction of the C18 and C19 stereocenters and C5-C10 chain extension as shown in Scheme 3. Hydroboration of spiroketal 4 followed by oxidation proceeded in good yield to afford the tertiary alcohol $\mathbf{1 0}$ as the only isomer. 


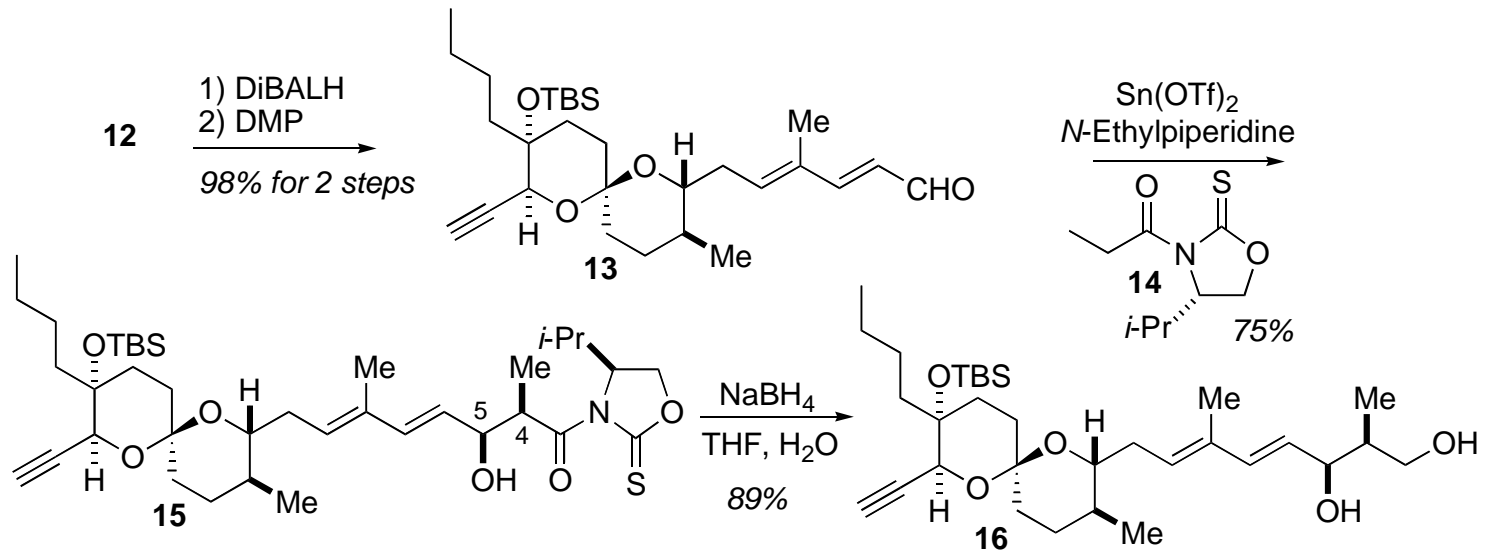

\section{Scheme 4}

The integrity of the 6,6-spiroketal $\mathbf{1 0}$ was evidenced by the characteristic ${ }^{13} \mathrm{C} \mathrm{NMR}$ chemical shift $(97.0 \mathrm{ppm})$ observed for the spiro carbon ${ }^{9,10}$ while the stereochemistry was confirmed by its conversion into a known reveromycin A degradation product ${ }^{4}$ as described previously. ${ }^{6}$ Protection of the tertiary alcohol followed by debenzylation afforded alcohol 11 ready for alkyne homologation. Oxidation ${ }^{16}$ of $\mathbf{1 1}$ and alkyne formation following the Bestmann protocol $^{17}$ then gave compound 3. Selective desilylation of the primary TBS group (TBAF, rt) followed by oxidation and two step Wittig extension provided the diene $\mathbf{1 2}$ in excellent overall yield for the four steps. Reduction of $\mathbf{1 2}$ and subsequent oxidation provided the substrate 13 required for the reagent controlled aldol reaction (Scheme 4). Treatment of aldehyde $\mathbf{1 3}$ with the tin enolate derived from oxazolidine-2-thione $\mathbf{1 4}^{9,18}$ afforded the desired syn-propionate 15 which when exposed to $\mathrm{NaBH}_{4}$ gave the diol $\mathbf{1 6}$ as a result of reductive auxiliary cleavage.

Removal of the $\mathrm{C} 18 \mathrm{TBS}$ ether required warming to $50^{\circ} \mathrm{C}$ to proceed at an appreciable rate and selective primary/secondary alcohol protection yielded bis-TBS ether 17 (Scheme 5). The stage was now set for the somewhat risky late stage introduction of the C18 hemisuccinate. Several methods for the acylation of hindered alcohols failed, ${ }^{19}$ affording mostly the isomerized 5,6-spiroketal as found in 2, so we turned to the application of high pressure according to the procedure described by Shimizu and Nakata., ${ }^{3,2}$ Thus, treatment of a mixture of alcohol 17 and monoprotected succinic acid $\mathbf{1 8}^{9 \mathrm{~b}}$ with DCC and DMAP at $0.4 \mathrm{GPa}$ in $\mathrm{CH}_{2} \mathrm{Cl}_{2}$ solvent gave the desired ester 19 in very high yield. Interestingly, we found that the reaction proceeded efficiently at much lower pressures than reported previously $(1.5 \mathrm{GPa})^{20}$ and required the use of relatively simple high pressure equipment. 


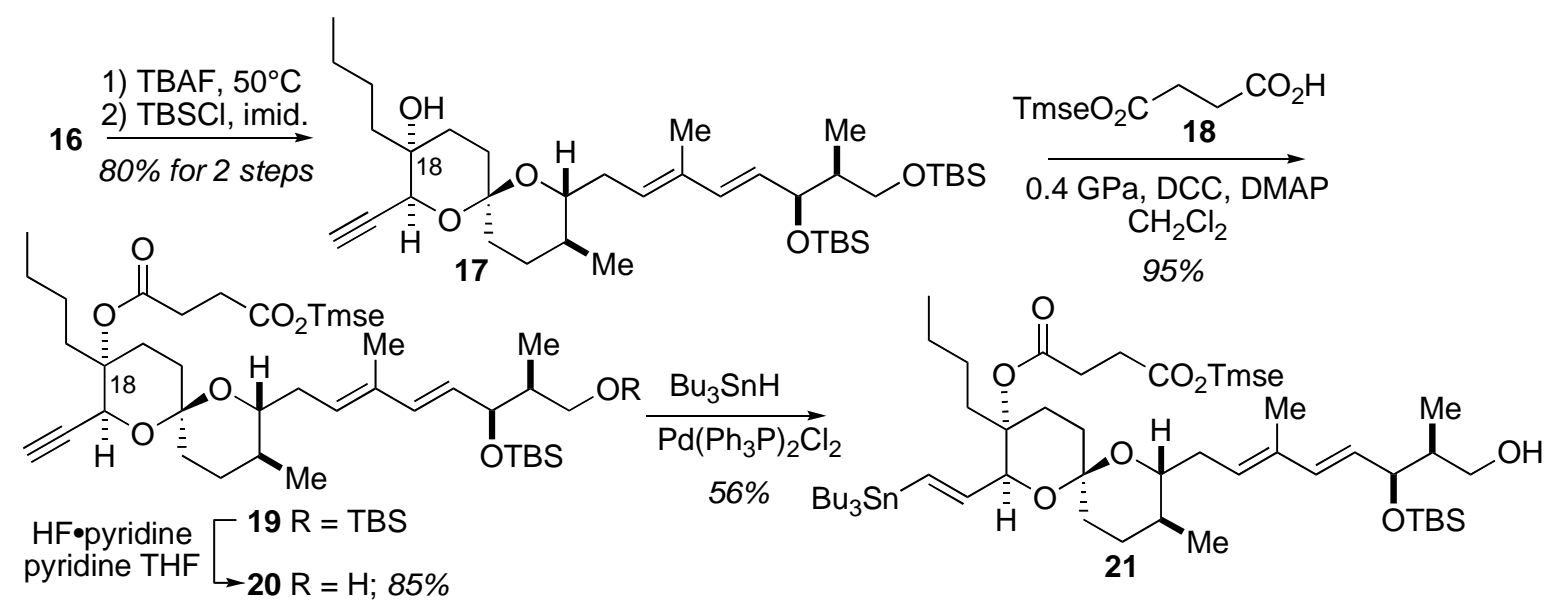

\section{Scheme 5}

Selective deprotection of the primary alcohol in $\mathbf{1 9}$ proceeded well using HF•pyridine complex buffered with pyridine ${ }^{21}$ to afford the alcohol 20. Hydrostannylation of the alkyne in 20 proved somewhat difficult under Pd catalyzed conditions ${ }^{22}$ owing to the steric hindrance at the axial alkyne functionality and excessive amounts of protodestannylation occurred during the reaction. We found that slow addition of the catalyst (up to $30 \mathrm{~mol} \%$ over $5 \mathrm{~h}$ ) was required to give the vinyl stannane $\mathbf{2 1}$ in acceptable yields.

The final steps to the target $\mathbf{1}$ are outlined in Scheme 6. Stille coupling ${ }^{23}$ between stannane 21 and vinyl iodide $22^{9 b}$ afforded the required tetraene 23 along with a small amount of what was tentatively identified as the 22E-isomer. This type of isomerization was observed by us during our studies on the total synthesis of reveromycin B (2). ${ }^{9}$ Oxidation of the free primary alcohol and Wittig extension ${ }^{24}$ afforded the fully protected reveromycin A precursor 24 which upon exposure to TBAF in DMF gave (-)-reveromycin A (1) in high yield. The synthetic material was purified by reverse phase chromatography (C18 SPE cartridge, $900 \mathrm{mg}, 40-60 \% \mathrm{MeOH} / \mathrm{H}_{2} \mathrm{O}$ ) and was identical (NMR, IR, UV, HRMS) to the natural product in all respects $\left\{[\alpha]^{22}-122.4(c\right.$, 0.16, MeOH); Lit. $\left.{ }^{1 \mathrm{~b}}[\alpha]_{\mathrm{D}}^{23}-115(c, 0.1, \mathrm{MeOH})\right\}$ including retention time on RP-HPLC. 


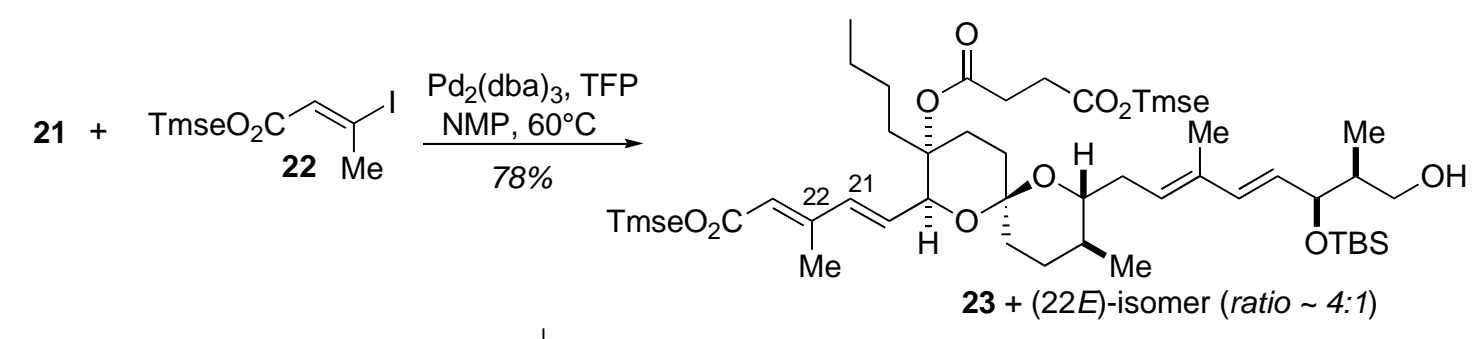

1) $\mathrm{DMP}$
2) $\mathrm{Ph}_{3} \mathrm{P}=\mathrm{CHCO}_{2} \mathrm{Tmse}$
$64 \%$

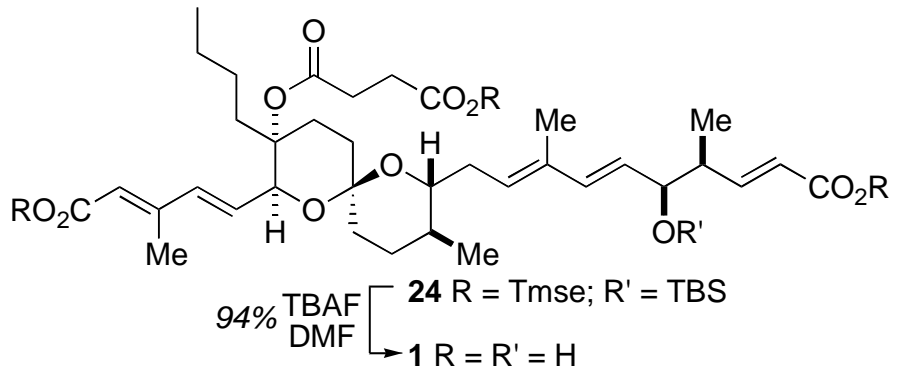

\section{Scheme 6}

In conclusion, we have completed the total synthesis of (-)-reveromycin A (1) which utilized a HDA reaction hydroboration sequence to construct the spiroketal core in a convergent and stereoselective manner.

\section{Total synthesis of the proposed structure for spirofungin B: a reassignment of the stereochemistry}

The spirofungins A (25) and B (26) were isolated from a Streptomyces strain Tü 4113 collected in the Otway National Park, Australia. ${ }^{25}$ Compounds 25 and 26 possess a similar 6,6-spiroketal core to reveromycin A (1) ${ }^{1}$ and have the same C1-C9 triene acid and C20-24 diene acid segments however there is no succinate half ester at C18 and the C18 substituent is a methyl group. The spirofungins show high inhibition activity against yeast and moderate activity against some fungi with a MIC of $15 \mathrm{\mu gmL}^{-1}$ against Candida albicans. ${ }^{25}$

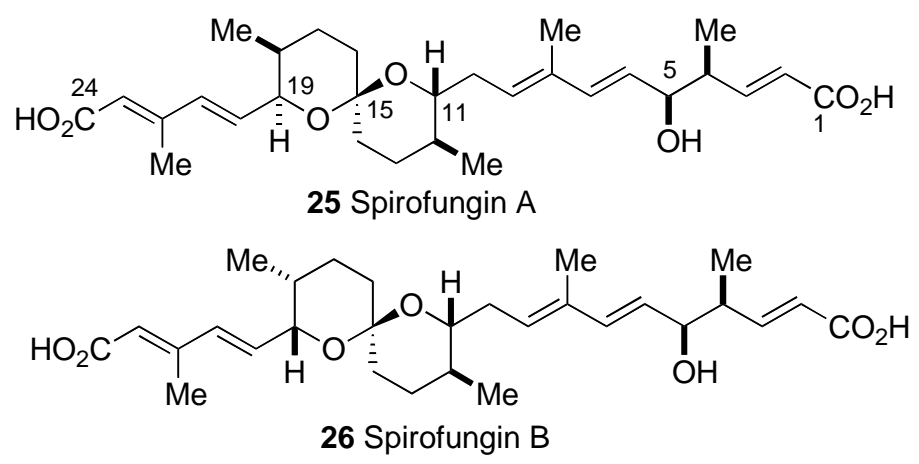


Compounds (25) and (26) were isolated as a $\sim 4: 1$ mixture respectively. Although they possessed slightly different retention times on reverse phase HPLC, they were not separated and the structural elucidation was conducted on this mixture. The structure of the major isomer spirofungin A (25) was assigned using various NMR techniques with the minor component spirofungin B (26) identified as a diastereoisomer of 25, epimeric at both C18 and C19. The absolute configurations of $\mathbf{2 5}$ and $\mathbf{2 6}$ are suggested by analogy to the reveromycins.

It was proposed $^{25}$ that the spiroketal core of $\mathbf{2 5}$ possessed the conformation $\mathbf{A}$ as depicted in Figure 2, with the oxygens (maximum anomeric stabilization) and the C19 diene acid sidechain in axial orientations while the C18 methyl group is equatorial. In compound 26, the C19 sidechain is now equatorial while the C18 methyl group is oriented axial as shown in proposed conformer B. This was supported by the vicinal coupling constant measured between H19 and H18, the C18 change in chemical shift, and the ROE observed between H19 and H11.
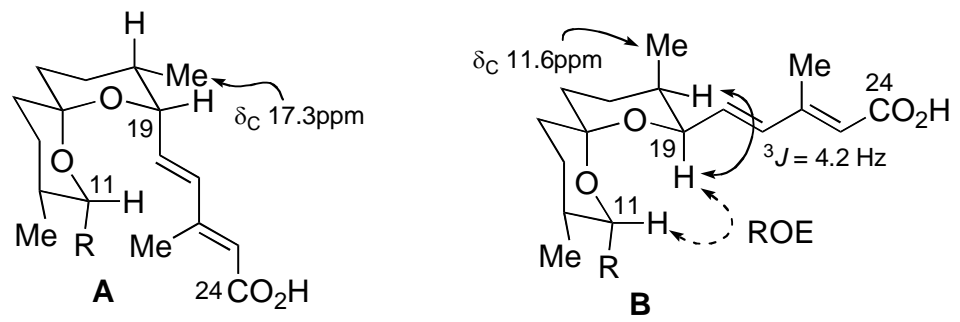

\section{Figure 2}

The natural occurrence of spirofungin B (26) is curious since it possesses a different absolute configuration at C19 to that from both spirofungin A (25) and the related reveromycins. Several groups have reported approaches ${ }^{26,27}$ to the spiroketal systems of spirofungins A (25). Herein, we detail our total synthesis of the structure $\mathbf{2 6}$ proposed for the minor component spirofungin B which lead to the reassignment of the stereochemistry of this natural product. ${ }^{28}$

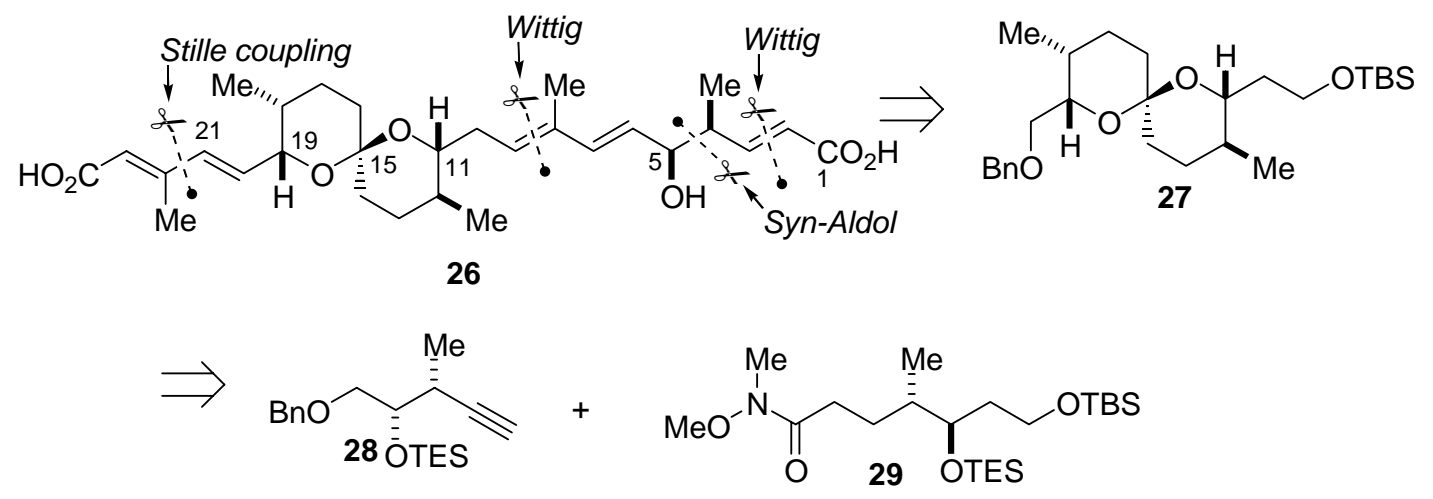

\section{Scheme 7}

A brief retrosynthetic analysis of $\mathbf{2 6}$ is shown in Scheme 7. The key bond disconnections 
are similar to those utilized for our total synthesis of reveromycin B (2). ${ }^{9}$ The C2-C3 and C8-C9 bonds could be formed via stabilized Wittig reactions while the the $\mathrm{C} 4-\mathrm{C} 5$ bond might be formed by a reagent controlled asymmetric syn-aldol reaction. ${ }^{18}$ Finally, the C21-C22 bond could be installed using a Stille cross coupling reaction. ${ }^{23}$ This leads to the key spiroketal intermediate 27 which could be constructed from a coupling ${ }^{29}$ between the anion derived from alkyne $\mathbf{2 8}$ and Weinreb amide $\mathbf{2 9}$ followed by alkyne saturation and acid induced deprotection and spiroketal formation. $^{13}$
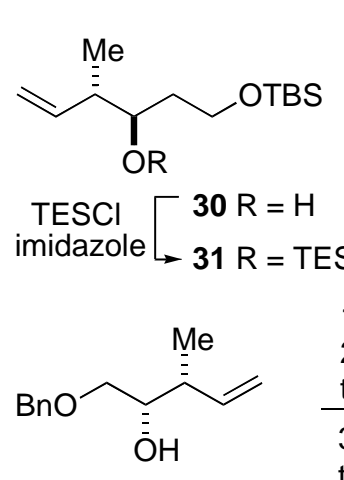

32

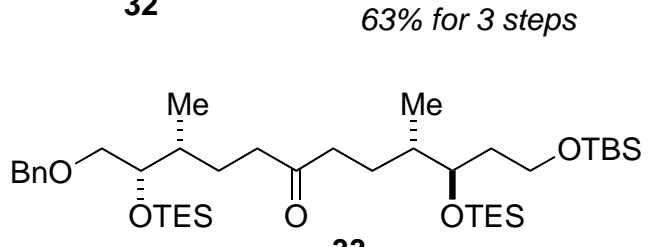

33

1) $\mathrm{TESCl}$, imidazole then $\mathrm{NaIO}_{4}$.

3) $\mathrm{Ph}_{3} \mathrm{P}, \mathrm{CBr}_{4}, \mathrm{CH}_{2} \mathrm{Cl}_{2}$ then $n$-BuLi

$63 \%$ for 3 steps

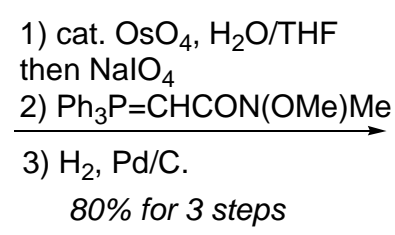

$80 \%$ for 3 steps

2) cat. $\mathrm{OsO}_{4}, \mathrm{H}_{2} \mathrm{O} / \mathrm{THF}$

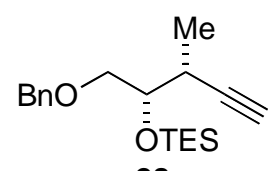

28<smiles>CON(C)C(=O)CC[C@@H](C)C(CC[OH+])[O+]C(F)(F)F</smiles>

29

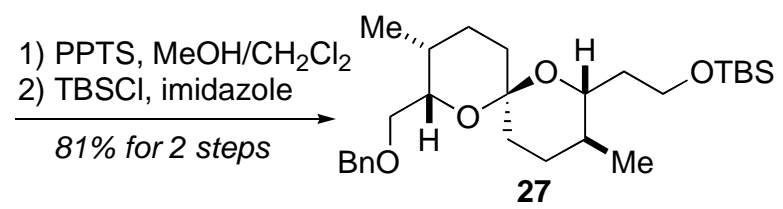

\section{Scheme 8}

The route to the proposed ${ }^{25}$ structure for spirofungin B began with the known optically pure alcohol $30^{9}$ (Scheme 8). 


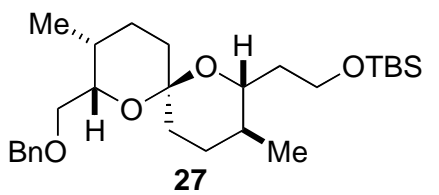

1) $\frac{\mathrm{H}_{2}, \mathrm{Pd} / \mathrm{C}, \mathrm{EtOAc}}{\text { 2) } \mathrm{DMP}, \mathrm{CH}_{2} \mathrm{Cl}_{2}, \mathrm{rt}}$

$\mathrm{MeOH}, \mathrm{K}_{2} \mathrm{CO}_{3}$ $60 \%$ for 3 steps

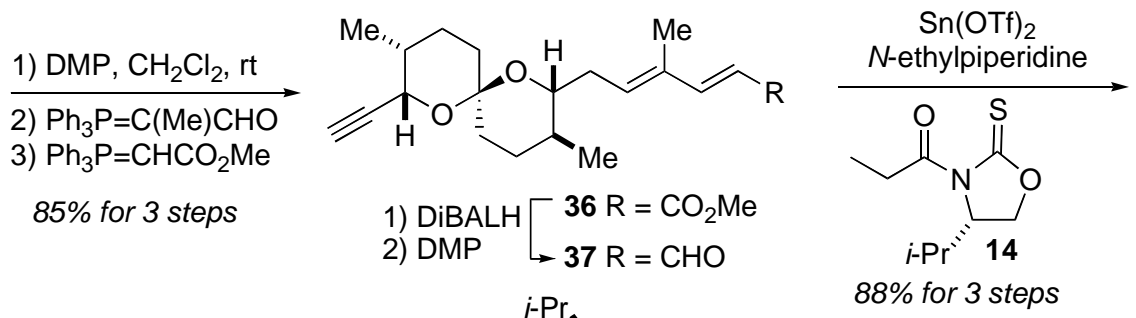

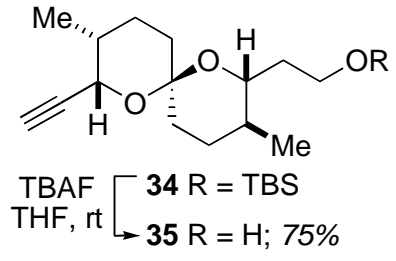

$\mathrm{Sn}(\mathrm{OTf})_{2}$

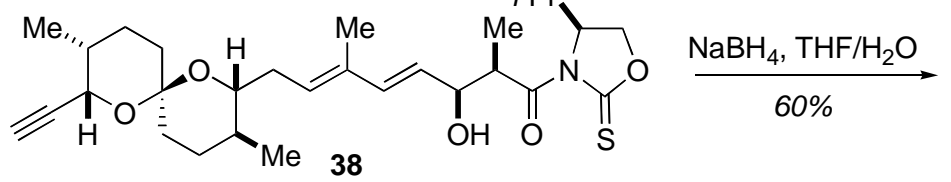<smiles>C#C[C@H]1O[C@]2(CCC1C)O[C@H](C/C=C(C)/C=C/C(O)C(C)CO)[C@@H](C)CC[C@@H]2C</smiles>

\section{Scheme 9}

Silylation of $\mathbf{3 0}$ gave ether $\mathbf{3 1}$ which was smoothly converted into Weinreb amide $\mathbf{2 9}$ by oxidative alkene cleavage, Wittig extension and hydrogenation.Coupling fragment 28 was synthesized from known alcohol $32^{30}$ by protection, alkene cleavage and Corey-Fuchs ${ }^{31}$ alkyne formation. Treatment of the alkyne $\mathbf{3 2}$ with $n$-BuLi followed by addition of the amide $\mathbf{2 9}$ and subsequent complete saturation using $\mathrm{H}_{2}$ and Lindlar catalyst gave the corresponding ketone 33 in excellent yield without any benzyl group removal. Compound $\mathbf{3 3}$ was subjected to acid deprotection and spiroketalization by treatment with PPTS in $\mathrm{MeOH}$ to give 27 as the only spiroisomer. Some of the primary TBS group was cleaved in this sequence but this was easily reinstalled by subjection of the crude product to resilylation. With the spiroketal fragment 27 in hand we next appended the C3-C10 sidechain as outlined in Scheme 9.

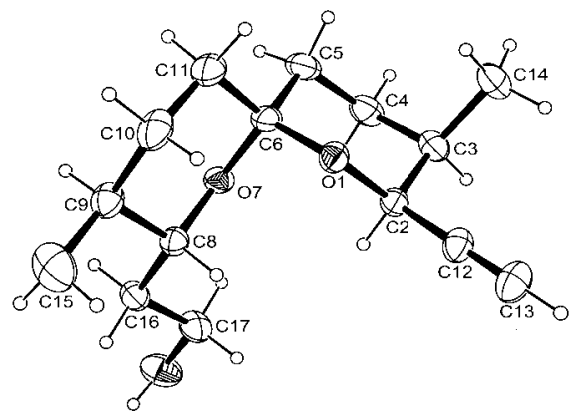

Figure 3. X-Ray structure of spiroketal 35. 
Debenzylation of 27 followed by oxidation $^{16}$ and homologation using the Bestmann protocol $^{17}$ gave alkyne 34. TBAF induced desilylation then afforded the alcohol 35 which fortunately was crystalline and an X-ray crystal structure ${ }^{32}$ was obtained for this intermediate confirming the stereochemistry (Figure 3).

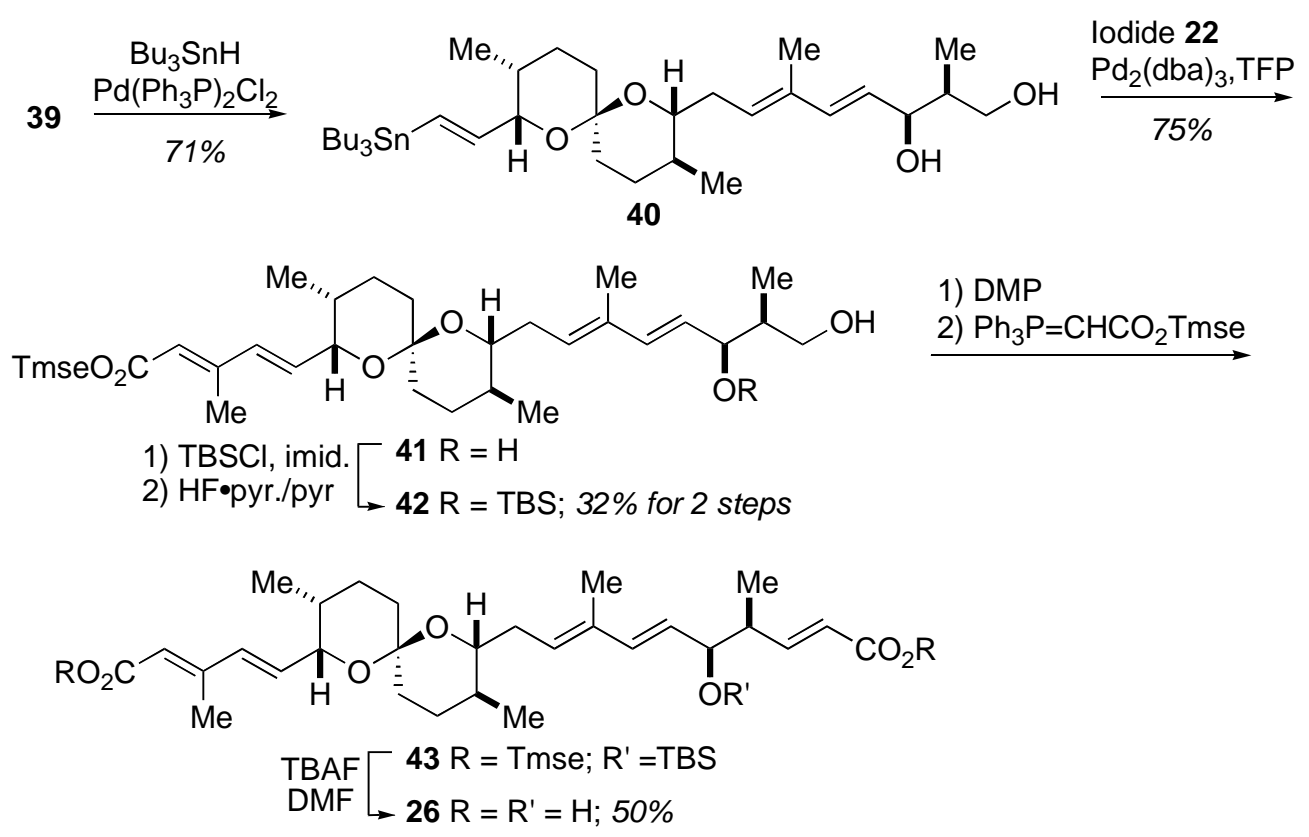

\section{Scheme 10}

Oxidation of alcohol $\mathbf{3 5}$ and sequential Wittig extensions gave the ester $\mathbf{3 6}$ in good yield. Adjustment of the oxidation level in $\mathbf{3 6}$ gave aldehyde $\mathbf{3 7}$ which underwent an asymmetric aldol reaction with the tin enolate derived from oxazolidine-2-thione 14 . $^{9}$ This sequence of reactions was high yielding and easily conducted on large scale. Auxiliary removal by treatment of $\mathbf{3 8}$ with $\mathrm{NaBH}_{4}$ in wet THF gave diol 39.

The final steps to compound $\mathbf{2 6}$ are outlined in Scheme 10. Conversion of alkyne $\mathbf{3 9}$ into vinyl stannane 40 using Pd catalysis ${ }^{22}$ proceeded in good yield. The stannane was then cross coupled $^{23}$ with the known iodide $22^{9}$ to cleanly provide ester $\mathbf{4 1}$ with the C20-C24 sidechain fully installed.

Protective group manipulation gave $\mathbf{4 2}$ which upon oxidation and Wittig reaction provided the protected precursor 43. Exposure of $\mathbf{4 3}$ to excess TBAF in DMF caused global deprotection to give the nominal structure for spirofungin B (26) which was purified by reverse phase HPLC. Unfortunately, the physical data obtained for synthetic $\mathbf{2 6}$ did not compare with that reported for spirofungin B. $^{25}$ Furthermore, the ${ }^{1} \mathrm{H}$ NMR spectrum of an authentic spirofungin mixture measured on the same instrument did not match our synthesized material. In particular, the chemical shift for $\mathrm{H} 19$ in the natural product (4.76 ppm) was vastly different to that found for compound 26 (4.29 ppm). In addition to other shift differences in the ${ }^{1} \mathrm{H}$ NMR spectrum, the 
chemical shift for $\mathrm{C} 15$ in the ${ }^{13} \mathrm{C}$ NMR spectrum of $\mathbf{2 6}$ was also measurably different to the literature value (Natural ${ }^{25}$ spirofungin B: 97.7 ppm. Synthetic 26: $96.2 \mathrm{ppm}$.) These differences lead to the obvious conclusion that the structure proposed for spirofungin B (26) is incorrect.
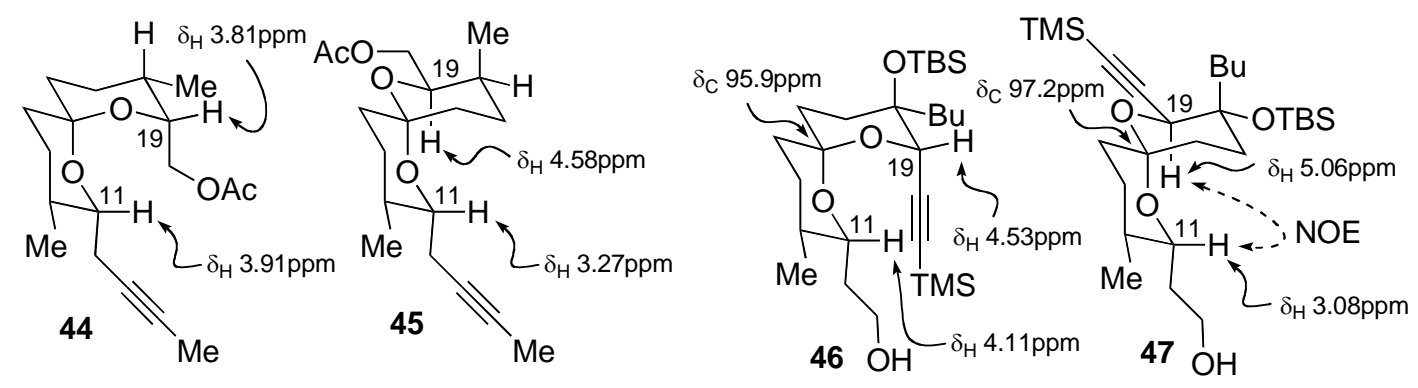

Figure 4. Related spiroketals (spirofungin numbering).

An investigation of the literature revealed a possible alternative for the structure of spirofungin B. In their synthesis of the spiroketal fragment of spirofungin A, Shimizu and coworkers $^{27}$ obtained a mixture of spiroketals $\mathbf{4 4}$ and $\mathbf{4 5}$ (ratio 1.53:1) isomeric at the spiro centre via a thermodynamic approach similar to that utilized above (Figure 4). This clearly demonstrates that isomerization of the spirofungin A spiroketal is possible under acidic conditions (due to the axial orientation of the C19 substituent) to afford a spiroketal with one less anomeric stabilization. ${ }^{33}$ The chemical shift for the H19 in the preferred isomer is upfield from the corresponding shift in the minor isomer where the axial H19 is deshielded by the axial oxygen $^{34}$ and the opposite change in chemical shift is evident for H11 (Figure 4). Comparable chemical shift differences are also observed for H11 and H19 in spirofungins A and B themselves (Figure 5). Another example can be found in the synthesis of the spiroketal fragment of reveromycin A (1). Theodorakis and co-workers ${ }^{7}$ also obtained a mixture of spiroketal isomers $\mathbf{4 6}$ and $\mathbf{4 7}$ in a ratio of 1.5:1 respectively by acid induced spiroketalization. The chemical shift differences (Figure 4) for the H11 and H19 protons for each isomer are similar to those cited above. In addition, the $\mathrm{C} 15$ chemical shifts for each isomer differ in a similar manner to that for spirofungin A $(95.7 \mathrm{ppm})$ verses B (97.7ppm). This is consistent with the trend of a slight downfield shift of the spiro carbon in going from ax-ax to ax-eq oxygen orientations. ${ }^{35}$ An NOE was also observed between H19 and H11 which was also seen in spirofungin B (Figure 2). 


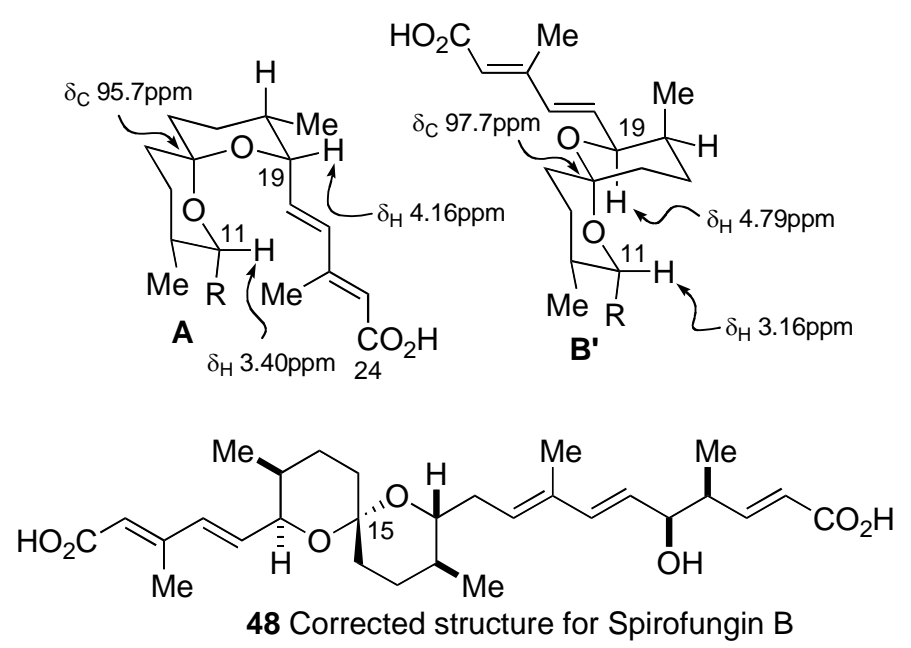

\section{Figure 5}

The results cited above strongly suggest that the structure for spirofungin B is in fact 15epi-spirofungin A (48) (Figure 5). The absolute configurations at C18 $(S)$ and C19 $(R)$ in spirofungin $B$ are identical to that for spirofungin A (26) while the spiro carbon is epimeric (15R). Spirofungin A (25) has the conformation A while pirofungin B has the conformation B' as shown in Figure 5 which is consistent with the NMR data presented. It is not unreasonable to suggest that biosynthetically, spirofungin A (26) could give rise to $\mathbf{4 8}$ by simple spiroketal isomerization in analogy to the spiroisomers of the pectenotoxins. ${ }^{36}$

\section{Acknowledgements}

We are indebted to Dr Hiroyuki Osada (RIKEN Institute, Japan) for an authentic sample of reveromycin A (1) as well as copies of the NMR spectra and Professors Hans-Peter Fiedler and Günther Jung (Tübingen University) for providing NMR spectra and an authentic sample of spirofungins A and B. We also thank Professor Rob Capon (University of Queensland) for the HPLC comparisons and Associate Professor Jonathan White (University of Melbourne) for the X-ray crystal structure. This work was financially supported by the Australian Research Council.

\section{References}

1. (a) Osada, H.; Koshino, H.; Isono, K.; Takahashi, H.; Kawanishi, G. J. Antibiot. 1991, 44, 259. (b) Takahashi, H.; Osada, H.; Koshino, H.; Kudo, T.; Amano, S.; Shimizu, S.; Yoshihama, M.; Isono, K. J. Antibiot. 1992, 45, 1409. (c) Takahashi, T.; Osada, H.; Koshino, H.; Sasaki, M.; Onose, R.; Nakakoshi, M.; Yoshihama, M.; Isono, K. J. Antibiot. 
1992, 45, 1414. (d) Koshino, H.; Takahashi, H.; Osada, H.; Isono, K. J. Antibiot. 1992, 45, 1420.

2. Miyamoto, Y.; Machida, K.; Mizunuma, M.; Emoto, Y.; Sato, N.; Miyahara, K.; Hirata, D.; Usui, T.; Takahashi, H.; Osada, H.; Miyakawa, T. J. Biol. Chem. 2002, 277, 28810.

3. Shimizu, T.; Masuda, T.; Hiramoto, K.; Nakata, T. Org. Lett. 2000, 2, 2153.

4. Shimizu, T.; Kobayashi, R.; Osako, K.; Osado, H.; Nakata, T. Tetrahedron Lett. 1996, 37, 6755.

5. $\quad$ Drouet, K. E.; Ling, T.; Tran. H. V.; Theodorakis, E. A. Org. Lett. 2000, 2, 207.

6. El Sous, M.; Rizzacasa, M. A. Tetrahedron Lett. 2000, 41, 8591.

7. (a) Drouet, K. E.; Theodorakis, E. A. J. Am. Chem. Soc. 1999, 121, 456. (b) Drouet, K. E.; Theodorakis, E. A. Eur. J. Chem. 2000, 6, 1987.

8. Masuda, T.; Osako, K.; Shimizu, T.; Nakata, T. Org. Lett. 1999, 1, 941.

9. (a) Cuzzupe, A. N.; Hutton, C. A.; Lilly, M. J.; Mann, R. K.; Rizzacasa, M. A.; Zammit, S. C. Org. Lett. 2000, 2, 191. (b) Cuzzupe, A. N.; Hutton, C. A.; Lilly, M. J.; Mann, R. K.; McRae, K. J.; Rizzacasa, M. A.; Zammit, S. C. J. Org. Chem. 2001, 66, 2382.

10. Zanatta, S. D.; White, J. M.; Rizzacasa, M. A. Org. Lett. 2004, 6, 1041.

11. Ubukata, M.; Koshino, H.; Osada, H.; Isono, K. J. Chem. Soc., Chem. Commun. 1994, 1877.

12. McRae, K. J.; Rizzacasa, M. A. J. Org. Chem. 1997, 62, 1196.

13. For the synthesis of spiroketals see: (a) Perron, F.; Albizati, K. F. Chem. Rev. 1989, 89, 1617. (b) Mead K. T.; Brewer; B. N. Curr. Org. Chem. 2003, 7, 227.

14. Bednarski, M.; Danishefsky, S. J. J. Am. Chem. Soc. 1983, 105, 3716.

15. Pale, P.; Bouquant, J.; Chuche, J.; Carrupt, P. A.; Vogel, P. Tetrahedron 1994, 50, 8035.

16. Dess, D. B.; Martin, J. C. J. Am. Chem. Soc. 1991, 113, 7277.

17. Müller, S.; Liepold, B.; Roth, G. J.; Bestmann, J. Synlett 1996, 521.

18. Nagao, Y.; Hagiwara, Y.; Kumagi, T.; Ochiai, M.; Inoue, T.; Hashimoto, K.; Fujita, E. J. Org. Chem. 1986, 51, 2391.

19. For example see: Zhao, H.; Pendri, A.; Greenwald, R. B. J. Org. Chem. 1998, 63, 7559.

20. Shimizu, T.; Hiramoto, K.; Nakata, T. Synthesis 2001, 1027.

21. Evans, D. A.; Gage, J. R.; Leighton, J. L. J. Am. Chem. Soc. 1992, 114, 9434.

22. Zhang, H. X.; Guibé, F.; Balavoine, G. J. Org. Chem. 1990, 55, 1857.

23. (a) Stille, J. K. Angew. Chem. Int. Ed. 1986, 25, 508. (b) Farina, V.; Krishnan, B. J. Am. Chem. Soc. 1991, 113, 9585.

24. Hungerbühler, E.; Seebach, D.; Wasmuth, D. Helv. Chim. Acta 1981, 64, 1467.

25. Holtzel, A.; Kempter, C.; Metzger, J. W.; Jung, G.; Groth, I.; Fritz, T.; Fiedler, H. -P. J. Antibiot. 1998, 51, 699.

26. Shimizu, Y.; Kiyota, H.; Oritani, T. Tetrahedron Lett. 2000, 41, 3141.

27. Shimizu, T.; Kusaka, J.; Ishiyama, H.; Nakata, T. Tetrahedron Lett. 2003, 44, 4965.

28. Zanatta, S. D.; White, J. M.; Rizzacasa, M. A. Org. Lett. 2004, 6, 1041.

29. Nahm, S.; Weinreb, S. M. Tetrahedron Lett. 1981, 22, 3815. 
30. Nicolaou, K. C.; Patron, A. P.; Ajito, K.; Richter, P. K.; Khatuya, H.; Bertinato, P.; Miller, R. A.; Tomaszewski, M. J. Chem. Eur. J. 1996, 2, 847.

31. Corey, E. J.; Fuchs, P. L. Tetrahedron Lett. 1972, 3769.

32. Crystallographic data have been deposited with the Cambridge Crystallographic Centre as supplementary publication CCDC-224793.

33. Deslongchamps, P.; Rowan, D. D.; Potheir, N.; Sauvé, G.; Sanders, J. K. Can. J. Chem. 1981, 59, 1105.

34. Ireland, R. E.; Daub, J. P. J. Org. Chem. 1983, 48, 1303.

35. Pothier, N. Goldstein, Deslongchamps, P. Helv. Chim. Acta 1992, 75, 604.

36. Sasaki, K.; Wright, J. L. C.; Yasumoto, T. J. Org. Chem. 1998, 63, 2475. 